\title{
Why is it so Hard to do a Good Thing? The Challenges of Using Reflection to Help Sustain a Commitment to Learning
}

\author{
Gail Frost, Maureen Connolly \& Elyse Lappano, Brock University
}

\begin{abstract}
Our service learning research includes assessment of reflective assignments done by students who apply theoretical knowledge in practical, real-life contexts by working with actual clients. For many of these students our classes are a departure from traditional forms of learning, and a challenge to their ability to apply what they know in often very unpredictable situations. The reflective assignments, which include field notes and journal entries, are designed to 1) train the professional competencies of client case management, writing and recording and 2) foster a sustained commitment to learning and professional development. This paper will describe several teaching and learning issues related to reflective writing which we have encountered in our students' work, and outline our plans to address them as we continue to promote critical thinking and reflection as important skills for our students to master.
\end{abstract}

Many of the students of physical education and kinesiology that we teach will pursue careers that involve one-on-one work with people, whether they be students in their class once they are qualified teachers, patients in their physiotherapy clinic, clients in their fitness centre or personal training business or children in a special needs activity program. Our service-based learning courses give students a chance to apply the theory they are learning in their degree programs in practical, real-life contexts before they graduate, by working with actual clients, designing and implementing physical activity programs with adults or engaging with children and youth with various disabilities. Students write a journal entry after each interaction with their client and use their collection of journal entries to complete a reflective writing assignment during the term. They also complete the Approaches and Study Skills Inventory for Students (ASSIST) questionnaire (Entwistle, Tait \& McCune, 2000). Analysis of the ASSIST suggests that the majority of our students are "strategic" learners: they are motivated to achieve the highest grade possible and are very alert to the assessment process. This is in contrast to the "deep" learner, who seeks meaning, relates and associates ideas, examines the evidence and engages with material with authentic curiosity and interest.

Service learning courses that want to be legitimate sites of authentic transformative learning will include an assessed reflective component. Our courses include the reflective assignment in part to support this essential element of service based and problem based learning, and also to provide the students with some "critical distance" from their own experiences. The required analysis of their journal entries is guided by a series of questions designed to position the learners as readers of their work as if it were a series of descriptions encountered after the fact. This critical distance allows them to view their own work and arrive at insights that might not be achieved if they were attempting to reflect while engaging simultaneously in the process of writing.

The raw material for our reflective writing comes from the students' journal entries which are written in a commonly used format: What? (What happened?), So What? (Why is it 
important?), Now What? (What does it mean and what is my response?). Both the journal entries and the reflective writing assignment are essential parts of our courses. We would like our students to learn not only the appropriate professional and ethical behaviour necessary for their future careers but, more importantly, how to think creatively and respond to changing circumstances. Mezirow (2000) has suggested that this type of learning should include understanding of context, critical reflection on assumptions and validation of meaning by assessing reasons.

We have encountered several teaching and learning issues over the course of two years of using this plan to encourage critical thinking and deep learning in our students. These include, from our students' perspectives: a seeming disconnect between instructions given and student response, missed opportunities for maximizing the advantage of ongoing process (e.g. not participating in iterative drafts), our examples becoming their "formulas" for writing, a desperate pursuit of the one "right" answer, minimizing the value of writing and reflection, and from our perspective: giving clear instructions that don't limit creative responses, challenges with assessment and giving timely, meaningful feedback.

Following the end of term assessment and submission of grades, we undertook a semiotic phenomenological analysis (Lanigan, 1988) of the journals of the students who had granted informed consent. We applied the basic steps of a semiotic phenomenological analysis, that is, description (reading for the whole, identifying literal elements, key words and idioms, summarizing patterns and salience, and attending to within-case details), reduction (further explaining patterns, salience, revelatory phrases and connections across the within-case and cross-case details), and interpretation (critically comparing the consolidated essential features to existing research and contextualizing the features within the research question).

At a literal level of description, we found that many students did not read, notice, or respond to instructions provided, omitted aspects of assignments or instructions, and did not follow suggested guidelines. We remain unsure about whether this is a factor of not understanding the instructions, of expedient decision making, or of not knowing how to ask for the kind of help that would allow them to understand what is being asked of them. Further, while most students completed the "What" section according to the guidelines, they were quite minimal in their responses to the "So What" and "Now What" sections.

At an interpretive level of reduction and description, we found that many students did not derive the desired meanings from the "So What" and "Now What" sections of their journals, perhaps because they were not used to keeping a journal and re-reading their own writing and reacting or responding to it. For those who embraced this as a project, both the quality of their writing and reflection improved as did other aspects of their placement, especially their planning and their consideration of the effectiveness of their planning and implementation. Students who did the "So What" and "Now What" sections minimally or thoughtlessly also did more minimal or thoughtless reflection and analysis. The opposite was also the case. Students who did these sections well also did more thoughtful and robust reflection and analysis. Students tend to do reflection on their emotional states and not on their actions and behaviours. When students reflected on action and behaviour as well as emotion, then they demonstrated improved insight about the interactions with their clients and their role within them. Summarizing this interpretive level of analysis, poor detail leads to superficial reflection. The opposite seems to be the case as well, but it is meaningful detail, not simply quantity of information, that makes the difference.

At a critical/applied level of interpretation, reduction and description, we found that reflection disconnected from action is not conducive to development of praxis (i.e. the blending 
of knowledge and action in implementation), and that fear of making mistakes or of receiving lower grades through trying different things seems to prevent some learners from moving to any form of dissonance and hence from trying non-habitual ways of engaging with material and people. If grades are the only form of achievement that students value, then strategic learning will not only be more prevalent, it may be the new imperative.

\section{Implications}

Our analysis led us to the following overarching thematic statements that consolidate the findings and will inform future course design:

- Learners need to see stronger and more obvious links to post graduate career/professional skills for material and assignments to feel relevant.

- Reading instructions and asking questions need more facilitation from the teacher in order for the learners to feel like they can engage with the purpose of the assignments as opposed to wondering what the teacher wants and attempting to shape their responses to that.

- Enactment of Vygotsky's zone of proximal development (1962) can foster "risk taking" if the groups and experiential placements can be organized for constant comparative interactions between groups engaged in similar experiences. For our students this might involve two groups working with the same type of client and discussing and comparing approaches, accommodations and preliminary outcomes.

- Deep learning requires a shift from a grading focus to a learning focus.

- Deep learning is best anchored in association, and meaningful association is more likely to involve having a sense of responsibility for how the experience unfolds. This supports our commitment to having our students work with real people in real life situations.

- Reflection can be powerful and transformative. Several learners had these experiences. As teachers, we need to build in more experiences for formative engagement and assessment as the reflective work is being done during the term.

\section{Next Steps}

One, 12-week course cannot "overcome" years of strategic, rule following, grade focused, reward oriented learning behaviours. Even though we wanted a "deep" learning experience for the learners in our classes, we could not compel or command it. We wanted to integrate their experience with their own reflection on it, but this often lead to manufactured reflections or reflections on emotions only and not on action or the reasoning behind the action. Metacognitive awareness of one's own process is a lofty goal. Going forward from the findings of this project, we are planning on separating the journal from the reflection, allowing more protocol driven and literal journaling based in professional field-note standards, and providing ongoing formative feedback on the quality of this journaling. The follow up reflections will be on prompts that are already based in situations of critical distance so that the students do not have to make that shift from their own writing. An example of our new recursive, reflective writing assignment follows. The parts will be completed one at a time, as the term progresses.

1. Describe your least preferred client, the type of client with whom you would not want to work, and why (relate "why" to your characteristics, specialty, training, background, interests, etc). 
2. Describe the type of practitioner that you think this least preferred client needs (i.e. the practitioner's characteristics, background, training, specialties, facility, etc).

3. Reflect on and describe what is preventing you from becoming that type of a practitioner.

4. Create your mission statement for your future practice. This statement should demonstrate how/why you belong in your profession, what you can offer your clients, and what makes you distinct.

We look forward to sharing our insights as the next phase of our project unfolds.

\section{References}

Entwistle, N., Tait, H. \& McCune, V. (2000). Patterns of response to an approaches to studying inventory across contrasting groups and contexts. European Journal of Psychology of Education, XV(1), 33-48.

Lanigan, R. (1988). Phenomenology of communication. Pittsburgh, PA: Duquesne University Press.

Mezirow, J. (2000). Learning to think like an adult. In J. Mezirow (Ed.), Learning as Transformation: critical perspectives on a theory in progress (pp. 3-33). San Francisco, CA: Jossey-Bass Inc.

Vygotsky, L.S. (1962). Thought and language (E. Hanfmann \& G. Vakar, Trans.). Cambridge, MA: MIT Press. 